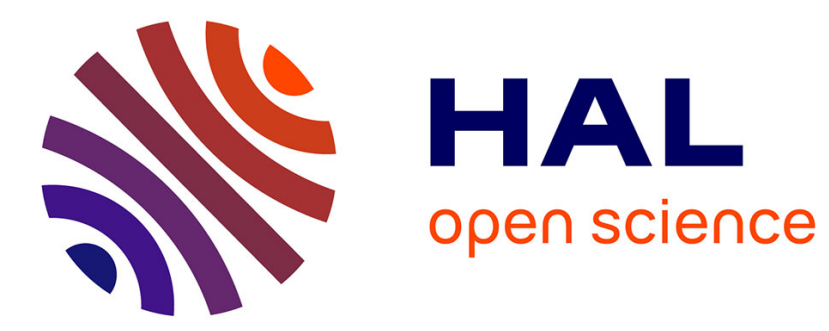

\title{
Mortality Inequalities by Parental Education among Children and Young Adults in Finland 1990-2004
}

\author{
Hanna Remes, Pekka Martikainen, Tapani Valkonen
}

\section{To cite this version:}

Hanna Remes, Pekka Martikainen, Tapani Valkonen. Mortality Inequalities by Parental Education among Children and Young Adults in Finland 1990-2004. Journal of Epidemiology and Community Health, 2010, 64 (2), pp.130-n/a. 10.1136/jech.2008.082388 . hal-00499242

\section{HAL Id: hal-00499242 https://hal.science/hal-00499242}

Submitted on 9 Jul 2010

HAL is a multi-disciplinary open access archive for the deposit and dissemination of scientific research documents, whether they are published or not. The documents may come from teaching and research institutions in France or abroad, or from public or private research centers.
L'archive ouverte pluridisciplinaire HAL, est destinée au dépôt et à la diffusion de documents scientifiques de niveau recherche, publiés ou non, émanant des établissements d'enseignement et de recherche français ou étrangers, des laboratoires publics ou privés. 


\section{Mortality Inequalities by Parental Education among Children and Young Adults in Finland 1990-2004}

Hanna Remes, Pekka Martikainen and Tapani Valkonen

Department of Sociology, University of Helsinki, Finland

Keywords: child mortality, age factors, socioeconomic factors, gender, trends

Abstract: 249 words

Text: $\quad 3209$ words excluding abstract, figures, tables and references.

"The Corresponding Author has the right to grant on behalf of all authors and does grant on behalf of all authors, an exclusive licence (or non exclusive for government employees) on a worldwide basis to the BMJ Publishing Group Ltd and its licencees, to permit this article (if accepted) to be published in JECH and any other BMJ Group products and to exploit all subsidiary rights, as set out in our licence (http://jech.bmjjournals.com//ifora/licence.pdf)"

Competing Interest: None declared.

\section{Correspondence to:}

Hanna Remes

Department of Sociology

P.O. Box 18 (Unioninkatu 35)

FI-00014 University of Helsinki, Finland

tel. +358919123885

fax +358919123967

email: hanna.remes@helsinki.fi 


\begin{abstract}
Background

Knowledge on health inequalities in early life is less complete and less consistent compared to the well-documented differentials in the adult population. This study examines the presence and strength of the association between parental education and mortality during different periods of childhood and young adulthood, and changes in the association over time.
\end{abstract}

\title{
Methods
}

Longitudinal individual level data was used in a register follow-up of 15 years. The data includes an $11 \%$ sample of the Finnish population with an over-sample of $80 \%$ of all deaths between ages 1-24. Mortality rates and relative indices of inequality (RII) were calculated by parental education, sex, age group and cause of death.

\section{Results}

Lower parental education was associated with a higher risk of mortality during the whole period 1990-2004. The differentials were largest among 1-4-year-old children (RII=2.4, 95\% CI 1.573.56 for males and RII=4.5, 2.71-7.32 for females) and among young men aged 15-19 (RII=2.4, $2.00-2.98)$. The educational gradient was sharper in accidental and violent causes of death, but deaths from diseases contributed to differentials for both sexes among the youngest and the oldest.

\section{Conclusion}

The association between parental education and mortality in young age was consistent, although distinctively patterned by sex, age, and cause of death. The results provide some support for the idea of equalisation of health inequalities during the child-youth transition. The convergence of differences in late childhood, and re-emergence in early adulthood particularly among men was, however, related to changes in the cause-composition of deaths. 


\section{Introduction}

Social gradients in health, wherein each successive level of higher social position enjoys better health, have been found in various health indicators. Mortality differentials in infancy and adulthood have been well-documented, but data on children and adolescents [1-6] is less complete and less consistent. Deaths in this age are relatively rare in developed countries, but the potential years of life lost are nevertheless greatest for mortality at the youngest ages. Moreover, studying mortality with large enough data can prove valuable as differentials in mortality reflect in all likelihood differentials in numerous other acute and chronic health conditions[7] that are more difficult to measure.

The presence and strength of the effects of socioeconomic factors on health vary by age. Childhood and adolescence involve many developmental changes, and identifying any coincident changes in the relationship between social position and health may provide clues to the mechanisms that produce health inequalities.[7] In this context West's hypothesis of relative equalisation in health during child-youth transition $[8,9]$ has received a lot of interest. In mortality, the age patterning of social differentials is closely related to differences in the causecomposition of deaths in particular age groups. Influenced by various factors, different causes of death are more or less likely to carry a social gradient.

Studying time trends in mortality differentials allows positioning the current stage of development in a larger context and helps to identify the conditions under which inequalities decrease or increase.[10] Such studies among young people are however relatively few. Roberts et al. evidenced widening relative differentials in injury mortality among $0-15$ year-olds between 1981 and 1991 in England and Wales [11], and although direct comparison was not feasible, the inequalities still remained in 2001-03.[12] Shaw et al. found a slight increase in relative mortality differences by income among children aged 1-14 in New Zealand between 1981 and 1999 , but no clear trend in differences according to maternal education or parental occupational class.[13] Widening inequalities by area-based socioeconomic measures have been evidenced among 1-14-year-old US children [14] and among 0-24-year-old males in Australia, where among females differentials instead decreased.[15]

In Finland, infant and child mortality rates are among the lowest in the world, but for adolescents and young adults, especially young men, the situation is less favourable.[16] Accidental and violent causes of death account for a major part of mortality among the young: their share of all deaths grows by age from less than $40 \%$ among $1-4$ year-olds to over $70 \%$ among $15-24$-yearolds.[17]

Mortality differentials by father's occupation-based social class among boys aged 5-14 were evident in Finland in the 1970s and 1980s. For girls, small differentials in the beginning of the 1980s nearly disappeared during the decade. Mortality differences according to father's level of education were also no longer of major significance at the end of 1980s, for neither boys nor girls.[18] In 1987-1995, Pensola and Valkonen [3] found no systematic gradient in all-cause mortality by parental class at ages 5-14 among females and 10-14 among males. In accidental and violent causes, however, females with manual class background had an excess mortality compared with the children of upper non-manual class at ages 10-19, and males at ages 5-9 and 
15-19. Among females at ages 15-19 and among males at ages 15-24 a social gradient appeared also in all-cause mortality. Differentials regarding injury-related mortality in adolescence by father's education and occupation were also evidenced among young males, but not females in 1979-2001.[19] More complete evidence on mortality differentials among young people is currently not available, and no evidence based on measures that would consider mother's socioeconomic position in two-parent households exists, even though young Finnish women are today more educated than men and, except for mothers with very young children ( $0-2$ years), often work full-time.[20]

This study aims to examine the presence and strength of the association between parental education and mortality during different periods of childhood and young adulthood, and to find out to what extent the association has changed over time in Finland. The mortality of children and young adults aged 1-24 years at death will be followed for a 15-year period from 1990 to 2004.

\section{Methods}

\section{Study population and participants}

This study is based on annually updated longitudinal register data obtained from Statistics Finland. The data set includes a representative $11 \%$ sample of the whole population residing in Finland during at least one of the years 1987-2003. Statistics Finland provides only crude data on the total population due to data-protection regulations. Therefore, to maintain statistical power in mortality analyses, the data set was complemented by a random over-sample of the population that died during the period so that altogether $80 \%$ of all deaths were covered. Appropriate weights for individuals from the original sample and the additional sample were used in the analyses to account for the unequal sampling probability.

As mortality in infancy differs significantly from the following years, this study was restricted to the young population of 1 to 24 years of age. The baseline at the end of 1989 consisted of individuals born in Finland in 1970 or after (subjects born before 1970 were excluded due to the amount of missing values on parental education). Children born in 1989 or later during the following 15 years entered the analysis on the month of their first birthday. Subjects became censored when reaching the age of 25 or at the end of the follow-up in 2004. A small number of emigrants became censored at the end of the calendar year preceding their move abroad.

Immigrants, who settled in Finland during the follow-up period, were not included in the analysis.

\section{Measurement of mortality and education}

The death statistics cover the deaths in Finland or abroad of persons who were at the time of death residents in Finland. The determination of the cause of death is based on the medical or forensic evidence providing the grounds for the issuing of a death certificate by a medical doctor.[17] Total mortality was broken down to different causes of death according to the ICD10 classification. For consistency, deaths due to the Asian Tsunami of December 2004 were excluded from analysis.

Level of parental education is based on the highest completed educational degree or certificate: those with basic qualifications have completed up to 9 years of education, those with secondary 
education 11-12 years, and those with higher education at least 13 years. To allow a common categorization for single and two-parent families, parental education was determined on the basis of the highest parental education in the household according to the dominance approach.

Children were linked to parents on a household basis, i.e. children were matched with the adult or adults they lived with, biological parents or not. Approximately $1 \%$ of children could not be linked to their parents. In general, this group that mostly consists of institutionalized children and children in foster care had the highest mortality, but as we had no further information on their living conditions the group was excluded from the analyses.

Information on completed education was registered yearly and the current value of parental education was used as long as the child lived with his/her parent/s; however in case of missing values for 16-year-olds or older (who might have already established their own households) we used the latest available value. Table 1 shows the distribution of parental education in different age groups and the person-years in the study population.

Table 1. Person-years and distribution (\%) of parental education by age group among 1-24year-olds in Finland 1990-2004.

\begin{tabular}{lrrrrr} 
& Age group & & & & \\
Parental education & $1-4$ & $5-9$ & $10-14$ & $15-19$ & $20-24$ \\
\hline Higher education & 49.6 & 47.6 & 44.2 & 39.9 & 35.9 \\
Secondary education & 41.1 & 42.0 & 42.6 & 41.9 & 40.8 \\
Basic education & 8.5 & 9.4 & 12.1 & 17.0 & 22.0 \\
Missing & 0.8 & 0.9 & 1.2 & 1.2 & 1.3 \\
\hline Total $^{\text {Person-years }}{ }^{1}$ & 100 & 100 & 100 & 100 & 100 \\
& 404355 & 520923 & 529404 & 529395 & 430622
\end{tabular}

${ }^{1}$ Unweighted total (as observed in the data)

\section{Statistical methods}

We estimated the association between parental education and the risk of death by calculating mortality rates and hazard ratios of mortality by parental education and cause of death. Attained age was used as the time scale in the univariate Cox regression models, and 5-year age groups were analysed separately, collapsing the groups when appropriate. The analyses were conducted separately for males and females.

To summarize the associations, we used relative indices of inequality (RII). Each of the original values of parental education was replaced by the midpoint of the cumulative proportion of the population that had a higher parental education, and mortality was then regressed on parental education as a continuous variable. This method for calculating RII assumes linear variation in incidence rates, and the value of RII can thus be interpreted as the relative increase in mortality between those at the high and low ends of the educational level hierarchy.[21] To begin with, we carried out all the analyses using parental education as a categorical variable, and found no such departures from linearity that should affect the conclusions drawn from the results. 


\section{Results}

During 1990-2004, children of 1-14 years of age whose parents had a secondary education carried a $37 \%$ higher mortality risk compared to children with higher educated parents and those with only basic parental education $83 \%$. The mortality rates indicated corresponding absolute differences in mortality, and largely similar associations were observed among adolescents and young adults of 15-24 years of age (table 2).

Table 2. Total mortality rates (per 100,000 person-years) and hazard ratios of death by parental education and broad age group among 1-24-year-olds in Finland, 1990-2004.

Mortality rates

Hazard ratios

\begin{tabular}{|c|c|c|c|c|c|c|c|c|}
\hline Parental education & 1-14 & $95 \% \mathrm{CI}^{1}$ & 15-24 & $95 \% \mathrm{CI}$ & 1-14 & $95 \% \mathrm{CI}$ & 15-24 & $95 \% \mathrm{CI}$ \\
\hline Higher education & 13.4 & $12.4-14.5$ & 46.8 & $44.2-49.5$ & 1.00 & & 1.00 & \\
\hline Secondary education & 18.2 & $17.0-19.5$ & 64.0 & $61.1-67.1$ & 1.37 & $1.23-1.52$ & 1.35 & $1.26-1.46$ \\
\hline Basic education & 24.0 & $21.3-27.2$ & 75.8 & 71.3-80.7 & 1.83 & $1.58-2.12$ & 1.54 & $1.42-1.68$ \\
\hline Number of deaths ${ }^{2}$ & 1777 & & 4176 & & & & & \\
\hline$\%$ accidental \& violent & 42 & & 75 & & & & & \\
\hline
\end{tabular}

Educational differentials in mortality were largest in the youngest age groups, and among young men of 15-24 years of age (fig 1 and table 3 ). In general, males had a higher level of mortality than females in all age groups. Among 1-4-year-olds, however, the relative differences (table 3) were stronger among girls due to the lower level of mortality in the reference group. In this age group the mortality rates for children with basic parental education were similar for both sexes, but among children with higher educated parents, girls had lower mortality than boys. On the contrary, in ages 15-24, differences in all-cause mortality were smaller among females than males both in absolute and relative terms.

Table 3. Relative indices of inequality by parental education, sex, age group, and cause of death among 1-24-yearolds in Finland, 1990-2004.

\begin{tabular}{|c|c|c|c|c|c|c|c|c|c|c|}
\hline Males & $1-4$ & $95 \% \mathrm{CI}^{1}$ & 5-9 & $95 \% \mathrm{CI}$ & 10-14 & $95 \% \mathrm{CI}$ & 15-19 & $95 \% \mathrm{CI}$ & 20-24 & $95 \% \mathrm{CI}$ \\
\hline All-cause mortality & 2.4 & $1.6-3.6$ & 2.4 & $1.5-3.7$ & 1.5 & $1.0-2.2$ & 2.4 & $2.0-3.0$ & 1.8 & $1.5-2.2$ \\
\hline Accidents \& violence & 4.0 & $2.0-8.3$ & 3.1 & $1.7-5.6$ & 1.5 & $0.9-2.5$ & 2.9 & 2.4-3.7 & 1.8 & $1.5-2.2$ \\
\hline Diseases & 1.9 & $1.1-3.1$ & 1.7 & $0.9-3.3$ & 1.5 & $0.8-2.8$ & 1.1 & $0.7-1.8$ & 1.8 & $1.3-2.7$ \\
\hline
\end{tabular}

Females

\begin{tabular}{|c|c|c|c|c|c|c|c|c|c|c|}
\hline All-cause mortality & 4.5 & $2.7-7.3$ & 2.0 & $1.2-3.2$ & 1.6 & $1.0-2.6$ & 1.4 & $1.0-2.0$ & 1.4 & $1.0-2.0$ \\
\hline Accidents \& violence & 5.8 & $2.2-15.0$ & 4.7 & $1.9-11.8$ & 2.2 & $1.1-4.5$ & 1.4 & $0.9-2.1$ & 1.3 & $0.8-2.0$ \\
\hline Diseases & 3.7 & 2.1-6.6 & 1.2 & $0.7-2.2$ & 1.2 & $0.6-2.4$ & 1.5 & $0.9-2.6$ & 1.7 & $1.0-2.8$ \\
\hline
\end{tabular}

The educational gradient was stronger in accidental and violent deaths (fig 1 and table 3): among males the association was present in each age group, except 10-14-year-olds. Among females aged 1-14, the differences were even larger than among males, but the small number of deaths does not allow for definitive conclusions. In contrast to males, no significant differentials 
according to parental education could be found among 15-24-year-old females in accidental and violent deaths. In terms of mortality from diseases, differentials existed for both sexes only in the youngest (1-4 years) and the oldest (20-24 years) age group.

To facilitate interpretation of the patterning of differences by age, we conducted separate analyses (results not shown) on the most common causes of death, which among 1-14-year-old children were traffic accidents, congenital malformations and chromosomal abnormalities, cancers and drowning. Higher mortality due to congenital malformations was associated with lower parental education, but only among 1-4-year-olds. By contrast, deaths caused by cancers did not carry an educational gradient. Traffic-related deaths were linked to parental education in each of the age groups; the association was nevertheless weakest among 10-14-year-olds.

Mortality due to drowning was strongly associated to lower education, but its contribution to mortality differentials lessened after ages 1-9 as the number of deaths by drowning dropped. In the ages 15-24, the cause-composition of deaths changed clearly. More than half of all deaths were caused by traffic accidents and suicides, which were both linked to parental education among young men, whereas among young women differentials were evidenced only in traffic deaths in the age group 15-19.

Changes in the association between parental education and mortality over time were tested by dividing the follow-up into three 5-year-periods, but the interaction term between parental education and period was not significant in any of the general or age- or cause-specific regression models. However, the mortality rates for the 5-year-periods of the follow-up (fig 2) indicated declining differentials among 1-14-year-old females, but widening differentials among males of the same age. The period-specific RII's suggested similar direction of change in the association. The large mortality differentials among 15-19-year-old males showed no clear trend: the differences seemed to diminish from the first to the second half of the 1990s, but then widen again (results not shown). Comparison between periods was not conducted for the 20-24year-olds due to the group's uneven age distribution in the first period.

\section{Discussion}

During the whole study period 1990-2004, lower parental education was associated with a higher risk of mortality in childhood and early adulthood. The differentials were patterned by sex, age group and cause of death. For males, the effect of parental education was clear among 1-9-year-olds, diminished in the age group 10-14, but then re-emerged in the age group 15-19. In the oldest age groups, where the over-representation of male deaths is largest, differentials were substantial also in absolute terms. For females, differentials were strongest among 1-4year-olds, and then gradually declined to a modest level among 15-24-year-olds.

Depending on the health outcome measured, both constant and age-varying socioeconomic gradients have been found within childhood and adolescence. $[9,22]$ These findings are hardly surprising considering the developmental changes during childhood, and the wide variety of factors that may contribute to the association between parental socioeconomic position and health. Regarding mortality, the presence and strength of social gradients differs likewise by cause of death, see for example Östberg.[1] Furthermore, the cause-composition of deaths is partly age-specific. In this study, the small mortality differentials in the age group 10-14 seemed to associate with age-related differences in the cause-composition of deaths: drowning was less 
common than among younger children, but suicides were still rare. The share of traffic accidents was instead higher (about a quarter of all deaths), but the link to parental education was weakest in this age. Consistent with the equalisation hypothesis, [8] this might be due to similar activities and exposures to risk at the age when children gain independence in traffic as pedestrians and bicyclists, but are not yet allowed to drive motor vehicles themselves.

The re-emergence of differentials among males in late adolescence is linked to personal risk behaviour, which is highlighted in the major causes of death. Suicides, traffic accidents, accidental poisonings and other accidents accounted for nearly 70\% of mortality among 15-19year-olds. The differentials reflect thus also the role of parental education as a determinant of young people's own educational and professional career, behaviour and attitudes. Previous research shows health-threatening behaviour such as high alcohol consumption and non-use of safety belts to be more common among lower socioeconomic groups.[23,24] For example, Mattila's study on injury-related deaths among young Finnish men, suggested the strongest predictive factor to be poor school success, followed by father's lower education, and own recurring drunkenness.[19] Traffic accidents and suicides were the leading causes of death also for young women, but lower parental education increased the risk only in traffic deaths, and to a lesser extent than among young men.

In developed societies, changes in mortality differentials have often been accompanied by a general decline in mortality, and changes in the size and composition of the groups of comparison. Identifying meaningful changes in the relative well-being of specific population groups is thus not a straightforward task. Scanlan argues that all measures of differences between binary outcomes are affected by the overall prevalence of an outcome and changes in it.[25] For example, declining mortality tends to be accompanied by increasing relative differentials. Departures from the expected patterns of change are still possible, as demonstrated by Houweling et al. in a cross-national comparison study.[26]

Despite considerable fluctuations in time, the level of mortality declined for both sexes during the whole period of this study. Among males, both absolute and relative differentials remained or even widened as those with higher educated parents benefited more from the decline, yet among 1-14-year-old females especially the last period 2000-04 showed declined differentials. Interestingly, this was also the period of greatest mortality decline. As opposed to males, the level of mortality for females in this age group may, however, already be approaching an irreducible minimum, and noting the indications of large relative differentials in accidental and violent deaths, considering only "avoidable" causes of death might have showed increased differentials instead.

The between-group differentials are affected by the relative size of the groups of comparison, and as the disadvantaged groups diminish in size, they tend to be comprised of even more disadvantaged individuals. On the one hand, the gradual decline of groups with only basic qualifications is likely to continue, which suggests that children with only basic parental education will be in an even further marginalised position and the relative excess mortality in this group may remain high also in the future. On the other hand, the great majority is doing better than ever.

Analysing the association between socioeconomic factors and child and youth mortality is prone 
to methodological difficulties arising from the relatively small number of deaths in the younger age groups. In statistical analysis the limited number of deaths results in wide confidence intervals in the mortality estimates, and often precludes more detailed analysis by socioeconomic subgroups, narrower age groups or time periods, and different causes of death. Using data on $80 \%$ of all young people's deaths in Finland from 15 years, we managed to overcome some of these difficulties. A further advantage of our data is almost no loss to follow-up.

Accumulating knowledge on socioeconomic health differentials is also challenging due to varying measures and classifications. The most commonly used indicators of socioeconomic position for children are parental income, education and occupation-based social class. These measures reflect partly different, but inter-related dimensions of a family's socioeconomic position, and the pathways and mechanisms through which they influence health differ likewise from material resources to knowledge and lifestyle factors. For the purposes of this study, where the aim was to confirm the existence of socioeconomic mortality differentials among young people and the analysis of mechanisms behind this association were left for further research, we chose to use parental education due to its reliability and annual register updates. Using a household-based measure according to the dominance approach allowed common categorization for one- and two-parent families and reduced the amount of missing values. Weaknesses of the approach are ignorance of biological links, and potential misclassification of children in joint custody as in Finland children can be registered in only one address. The amount of such families is yet still too small to significantly alter the results of the analyses.

To conclude, educational inequalities in the risk of death still existed in Finland in 1990-2004. The association between parental education and mortality was present among both sexes, and in almost all periods of childhood and young adulthood. The association was stronger in accidental and violent causes of death, but deaths from diseases contributed significantly to differentials especially in early childhood and young adulthood. Comparison between the three 5-year periods of follow-up indicated persisting mortality differentials during the whole 15 years.

The results provide some evidence of convergence of mortality differences in late childhood and re-emergence in early adulthood particularly for accidental and violent causes of death among young men, thus supporting West's idea [8] of equalisation of health inequalities in late childhood. To the extent that the processes that underlie social differences in mortality in childhood and early adulthood - such as behavioural patterns - persist into adulthood, we may expect adult health differences to persist as these cohorts age.

\section{Acknowledgements}

The study was supported by the Ministry of Social Affairs and Health in Finland and Academy of Finland. We thank Statistics Finland for granting access to the data (permission TK 53-60106).

\section{What this paper adds}

What is already known on this subject?

- Despite continuous mortality decline, socioeconomic inequalities in mortality among young people still exist in many developed countries.

- Studies have shown widening, but also stable or diminishing differentials over time. 
- Incomplete evidence also on patterning of differentials by sex, narrower age groups, and different causes of death.

What does this study add?

- Based on a large, population-representative sample and a 15-year follow-up, level of parental education was systematically associated with mortality in childhood, adolescence and young adulthood.

- For males the age-patterning of the association was u-shaped, with negligible differences among 10-14-year-olds, whereas for females the differentials gradually declined by age.

- The age-patterning of differentials is partly explained by changes in the causecomposition of deaths.

- Trends over time remained unclear, except for some indication on widening differentials among 1-14-year-old males, and diminishing differentials among females of same age.

\section{References}

1 Östberg V. Social structure and children's life chances: an analysis of child mortality in

Sweden [dissertation]. Stockholm: Swedish Institute for Social Research 1996:26.

2 Hussey JM. The effects of race, socioeconomic status, and household structure on injury mortality in children and young adults. Maternal and Child Health Journal 1997;1(4):217-227.

3 Pensola TH \& Valkonen T. Mortality Differences by Parental Social Class from Childhood to Adulthood. J Epidemiol Community Health 2000;54:525-529.

4 UNICEF. A league table of child deaths by injury in rich nations. Innocenti Report Card No.2, 2001. Florence: UNICEF Innocenti Research Centre.

5 Engström K, Diderichsen F, Laflamme L. Socioeconomic differences in injury risks in childhood and adolescence: a nation-wide study of intentional and unintentional injuries in Sweden. Inj Prev 2002;8:137-142.

6 Petrou S, Kupek E, Hockley C, Goldacre M. Social class inequalities in childhood mortality and morbidity in an English population. Paediatr Perinat Epidemiol 2006;20(1):14-23.

7 Chen E, Matthews KA \& Boyce WT. Socioeconomic differences in children's health: How and why do these relationships change with age? Psychol Bull 2002;128:295-329.

8 West P. Health inequalities in the early years: Is there equalisation in youth? Soc Sci Med 
1997;44(6):833-58.

9 West P \& Sweeting H. Evidence on equalisation in health in youth from the West of Scotland. Soc Sci Med 2004;59(1):13-27.

10 Houweling TAJ, Kunst AE, Borsboom G, Mackenbach JP. Mortality inequalities in times of economic growth: time trends in socioeconomic and regional inequalities in under 5 mortality in Indonesia, 1982-1997. J Epidemiol Community Health 2006;60:62-68.

11 Roberts I, DiGuiseppi C, Ward H. Childhood injuries: extent of the problem, epidemiological trends, and costs. Inj Prev 1998;4:S10-S16.

12 Edwards P, Roberts I, Green J, Lutchmun S. Deaths from injury in children and employment status in family: analysis of trends in class specific death rates. BMJ 2006;333:119. Published 7 July 2006. doi:10.1136/bmj.38875.757488.4F

13 Shaw C, Blakely T, Atkinson J, Crampton P. Do social and economic reforms change socioeconomic inequalities in child mortality? A case study: New Zealand 1981-1999. J Epidemiol Community Health 2005;59:638-44.

14 Singh GK \& Kogan MD. Widening socioeconomic disparities in US childhood mortality, 1969-2000. Am J Public Health 2007;97(9):1658-65.

15 Turrell G \& Mathers C. Socioeconomic inequalities in all-cause and specific cause mortality in Australia: 1985-1997. Int J Epidemiol 2001;30:231-239.

16 Koskinen S, Aromaa A, Huttunen J, Teperi J (eds.). Health in Finland. Helsinki, Finland:

National Public Health Institute (KTL), National Research and Development Centre for Welfare and Health (STAKES), and Ministry of Social Affairs and Health, 2006.

17 Statistics Finland. Causes of Death 2004. Health 2005:1. Helsinki: Statistics Finland.

18 Rimpelä A. Children. Adolescents and Young Adults. In: Valkonen T, Martelin T, Rimpelä

A, et al. Socio-economic Mortality Differences in Finland. Helsinki: Statistics Finland 1993:20- 
32.

19 Mattila V. Injuries and Their Risk Factors in Finnish Adolescents [dissertation]. Tampere: Acta Universitatis Tamperensis 1085. Tampere University Press 2005.

20 Haataja A. Family leave and employment in the EU: transition of working mothers in and out of employment. In: Pfau-Effinger B \& Geissler B (eds.) Care and Social Integration in European Societies. Bristol: The Policy Press 2005:255-278.

21 Mackenbach JP, Kunst AE. Measuring the magnitude of socio-economic inequalities in health: an overview of available measures illustrated with two examples from Europe. Soc Sci Med 1997;44:757-71.

22 Chen E, Martin DM \& Matthews KA. Socioeconomic status and health: Do gradients differ within childhood and adolescence? Soc Sci Med 2006;62(9):2161-2170.

23 Petridou E, Zavitsanos X, Dessypris N, Frangakis C, Mandyla M, Doxiadis S, Trichopoulos D. Adolescents in high-risk trajectory: clustering of risky behavior and the origins of socioeconomic health differentials. Prev Med 1997;26(2):215-9.

24 Droomers M, Schrijvers CT, Casswell S, Mackenbach JP. Occupational level of the father and alcohol consumption during adolescence; patterns and predictors. J Epidemiol Community Health 2003;57(9):704-10.

25 Scanlan JP. Race and mortality. Society 2000;37(2):19-35.

26 Houweling TAJ, Kunst AE, Huisman M, Mackenbach JP. Using relative and absolute measures for monitoring health inequalities: experiences from cross-national analyses on maternal and child health. Int J Equity Health 2007;6:15. Published online 29 October 2007. doi:10.1186/1475-9276-6-15 
Figure 1. Mortality rates (per 100,000 person-years) by level of parental education and age group. 1-24-year-old males (top) and females (bottom), Finland, 1990-2004.
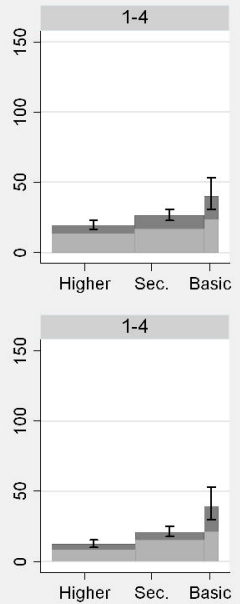

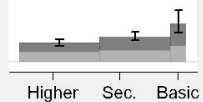

$$
5-9
$$

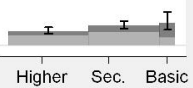

$10-14$

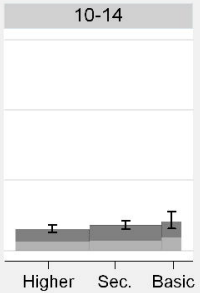

$10-14$

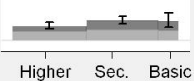

$15-19$

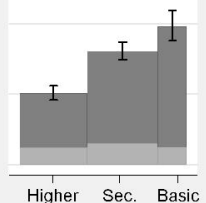

$15-19$

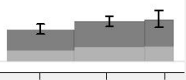

Higher Sec. Basic
$20-24$

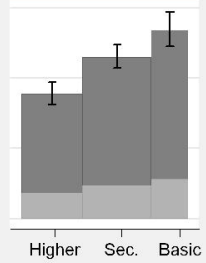

$20-24$

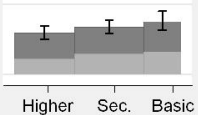

The graph depicts all-cause mortality rates with $95 \%$ confidence intervals. The bars are divided into two areas: the lighter area represents mortality due to diseases and the darker area mortality due to accidents and violence. The width of the bars is directly proportional to the distribution (\%) of parental education in each age group. 
Figure 2. Mortality rates (per 100,000 person-years) and relative indices of inequality (RII) with $95 \%$ confidence intervals by parental education and period. 1-14-year-old males (top) and females (bottom), Finland, 1990-2004.
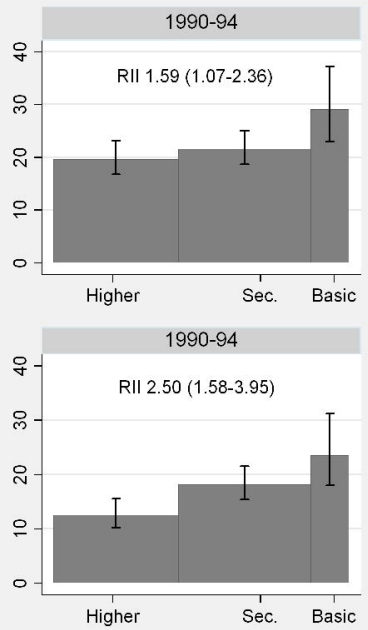

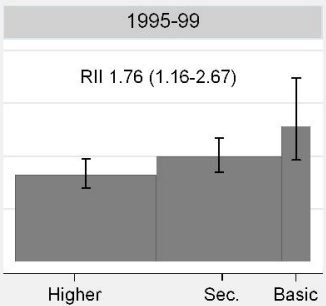

$1995-99$

RII 2.43 (1.51-3.89)

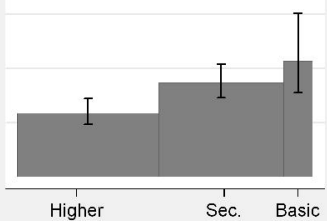

$2000-04$

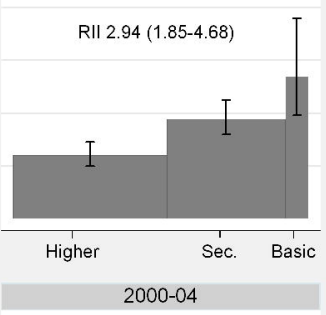

RII $2.01(1.14-3.56)$

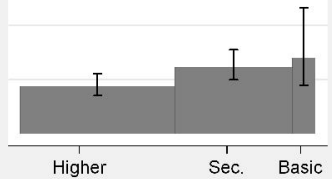

The graph depicts all-cause mortality rates with $95 \%$ confidence intervals. The width of the bars is directly proportional to the distribution (\%) of parental education in each period. 